\title{
Energy efficiency estimation of a steam powered LNG tanker using normal operating data
}

\author{
Rajendra Prasad Sinha ${ }^{1}$ \\ ${ }^{1}$ Department of advanced Marine Engineeringt, Malaysian Maritime Academy \\ Kuala Sg Baru Post code 78300, Masjid Tanah, Melaka,Malaysia \\ rajendra@alam.edu.my \\ ph 06-3882200, fax 063876700
}

\begin{abstract}
A ship's energy efficiency performance is generally estimated by conducting special sea trials of few hours under very controlled environmental conditions of calm sea, standard draft and optimum trim. This indicator is then used as the benchmark for future reference of the ship's Energy Efficiency Performance (EEP). In practice, however, for greater part of operating life the ship operates in conditions which are far removed from original sea trial conditions and therefore comparing energy performance with benchmark performance indicator is not truly valid. In such situations a higher fuel consumption reading from the ship fuel meter may not be a true indicator of poor machinery performance or dirty underwater hull. Most likely, the reasons for higher fuel consumption may lie in factors other than the condition of hull and machinery, such as head wind, current, low load operations or incorrect trim [1]. Thus a better and more accurate approach to determine energy efficiency of the ship attributable only to main machinery and underwater hull condition will be to filter out the influence of all spurious and nonstandard operating conditions from the ship's fuel consumption [2]. The author in this paper identifies parameters of a suitable filter to be used on the daily report data of a typical LNG tanker of $33000 \mathrm{~kW}$ shaft power to remove effects of spurious and non-standard ship operations on its fuel consumption. The filtered daily report data has been then used to estimate actual fuel efficiency of the ship and compared with the sea trials benchmark performance. Results obtained using data filter show closer agreement with the benchmark EEP than obtained from the monthly mini trials. The data filtering method proposed in this paper has the advantage of using the actual operational data of the ship and thus saving cost of conducting special sea trials to estimate ship EEP. The agreement between estimated results and special sea trials EEP is expected to improve further with use of better and more accurate filtering techniques.
\end{abstract}

Key words: Ship Energy Efficiency, Specific Fuel Rate, LNG, Shaft Power, Hull fouling

\section{Introduction}

It is common practice to conduct specially designed controlled sea trials to estimate a benchmark ship EEP to be used for future comparison during ship's actual operation. This benchmark index, although more accurate, is less related to the real life situations in which the ship actually sails because the operating environment is very different [1]. For a meaningful comparison with benchmark index an effective EEP of the ship should be extracted from the actual operating parameters which will then reflect truly on the condition of its machinery and hull fouling [2] which is the main purpose of performance monitoring.

The fuel efficiency of a ship is determined by measuring the quantity of fuel consumed to produce the required amount of propulsion and auxiliary power to move the ship at a specified speed. Lesser the quantity of fuel used the ship is considered more efficient. This efficiency has been measured in many different units but the one most universally accepted by the International shipping community is the Specific Fuel
Rate (SFR). The SFR is expressed in grammes of fuel consumed for every $\mathrm{kWh}$ of power produced by the main propulsion machinery plus electrical generators [3], expressed as:

$$
\text { Vessel SFR }=\frac{\text { Fuel Consumed at sea per Dayin grammes }}{\text { Total }(S H P+T / G \text { power }) k W h}\left[\frac{g m}{k W h}\right]
$$

Typical sample plots of SFR estimates from daily report of January and February 2014 for the ship under investigation are shown in figure 1. These plots show very inconsistent variations in the SFR of the ship. It is observed, on a particular day the ship performs well but then next day the SFR rises very high followed by again a sudden drop indicating improvement in fuel consumption.

Corresponding author: rajendra@alam.edu.my 

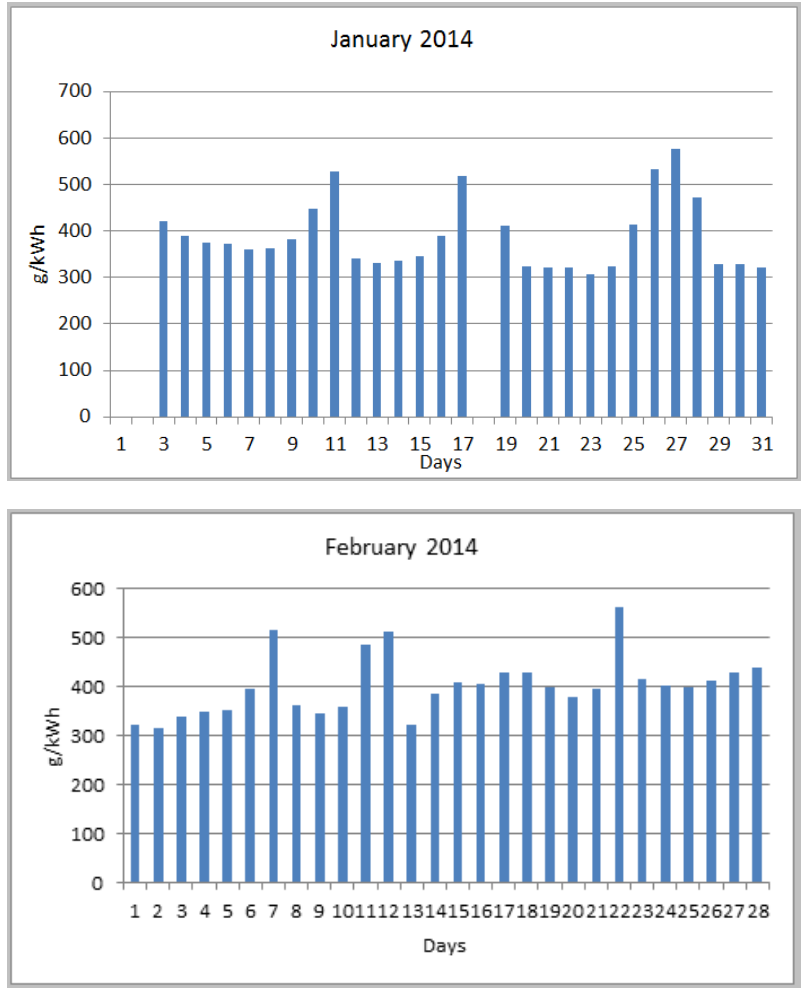

Figure 1. Sample SFR from Daily report

Obviously this kind of random variations in ships fuel efficiency cannot be attributed to hull condition or machinery. Most likely the cause of high SFR fluctuation could be some external factor such as the sea environment or operating procedures. Hence, to achieve accurate SFR estimates, the adverse effect of these factors on the fuel consumption needs to be filtered out. The author in this paper aims to answer this question by proposing a suitable data filter.

\section{Data Acquisition and Management}

An automatic data monitoring system is installed in the ship to record 24 hourly average value of following operational parameters which is then sent to the main office as daily report $[3,4]$.

\section{(i) Ship speed in knots}

(ii) Duration of operation at specific speed in hours

(iii) SHP for duration of specific speed

(iv) Shaft rpm for duration of specific speed

(v) Liquid fuel consumption for the duration of specific speed, tons

(vi) Gas fuel consumption for the duration of specific speed, tons

(vii) Total equivalent fuel consumption for the duration of specific speed, tons

(viii) Distance covered by the ship at specific speed by ship's Log, nautical miles

(ix) Distance covered by the ship at specific speed by GPS, nautical miles (x) Relative wind speed in knots and direction with respect to ship's heading, degree

Daily report entries also include summary of energy performance estimates, propeller slip and total power produced by the main engine and generators for the daily voyage. Fuel consumed during maneuvering and in port stay are entered separately. Typical daily report sample is shown in table 1 .

\section{Energy Efficiency Estimation}

The shipboard performance monitoring system estimates ship EE by measuring the total fuel consumed by the ship in 24 hours (converted in grammes), Equation (1) and then dividing it by the kilo-watts average over the same period as in Equation (2). Algebraically, EE is expressed as in Equation 3.

Total fuel consumed during 24 hour voyage,

$$
\mathrm{Q}=\sum_{i=1}^{N} q_{i}
$$

$$
\mathrm{SHP}_{\text {average }}=\frac{\sum_{i=1}^{N} P_{i} \times t_{i}}{\sum_{i=1}^{N} t_{i}}
$$

$$
\text { Ship SFR }=\frac{Q}{S H P_{\text {average }}}
$$

The ship SFR in voyage leg method is calculated using equation $4 \& 5$.

$$
\begin{gathered}
\mathrm{SFR}_{\mathrm{Leg}(\mathrm{i})}=\frac{q_{i}}{P_{i}}, \\
\mathrm{SFR}_{\mathrm{E}(\mathrm{i})}=S F R_{\operatorname{Leg}(i)} \times \frac{t_{i}}{\sum_{i=1}^{N} t_{i}}
\end{gathered}
$$

Ship daily energy efficiency performance ,

$$
\text { Ship SFR }=\sum_{i=1}^{N} S F R_{E(i)}
$$

$P_{\mathrm{i}}=($ Shaft power + Generator power $)$ for specific voyage leg, $\mathrm{kW}$

$\mathrm{t}_{\mathrm{i}}=$ Voyage leg duration, hour

$\mathrm{q}_{\mathrm{i}}=$ Voyage leg fuel consumption, grams

$\mathrm{N}=$ Number of voyage legs in a 24 hour sea passage

\section{Ship Energy Efficiency Analysis [2,4,5]}

The daily report data of the ship from January-December 2014 has been considered for analysis. The benchmark SFR of $300 \mathrm{~g} / \mathrm{kWh}$ from the original sea acceptance trial 
report conducted by the shipbuilder has been used for comparison of ship energy efficiency in this analysis. KYMA system recorded SFRs for both months in fig 1 are above benchmark acceptable level. For instance, on days 11,17 in January and 12, 22 in February the SFR is over $500 \mathrm{~g} / \mathrm{kWh}$ while on many days during this intervals the SFR is very close to the benchmark of $300 \mathrm{~g} / \mathrm{kWh}$. But the physical nature of the machinery and hull aging process should show a gradual change in the SFR with time. Therefore, this kind of abrupt variation in SFR readings cannot be used to predict actual condition of the machinery or growth in underwater hull fouling which is the chief objective of ship energy efficiency monitoring.

\section{Voyage Leg Analysis}

To determine actual SFR of the ship from daily report data, voyage leg analysis method has been used which works as follows. A day's voyage of 24 hours is generally made of a number of short voyage legs of few hours each with ship sailing at different speeds and shaft power. Also each voyage leg of a particular day's sailing is entered separately in the daily report with corresponding fuel consumption data. Therefore, by using Equation 3, it is possible to determine the SFR of an individual voyage leg of a 24 hours voyage together with its actual contribution to the day's overall SFR. A voyage leg with small or insignificant contribution to the overall day's SFR may be then treated as spurious operating noise source which is not truly related to ship energy system performance and hence can be ignored without causing serious error to the day's overall SFR estimate. The voyage leg SFR analysis can be thus used as filter to remove all spurious and non-standard operating conditions which will then give more steady and accurate SFR estimate of a 24 hours day's voyage. This estimation method has been used by the author to determine true SFR of the ship. Table 1 shows details of sample voyage legs, durations, shaft power and corresponding fuel consumption on four different days in January 2014 when recorded SFRs are high (ship's energy performance is low).

\section{Results and Discussions [2,3,5]}

Result of analysis using voyage leg method to estimate actual effective SFR of 24 hour voyage for January and February 2014 in figure 1 is discussed in this section. Day 11 in January had three distinct voyage legs with corresponding SFR and their impact on the effective SFR as shown in figure 2(a). The impact of voyage leg 1 on the overall effective SFR is very small which is indicative of a non-standard ship operation that does not really relate to actual machinery or hull condition. Therefore, the true ship effective SFR for 11 January 2014 voyage may be quite accurately estimated from the sum of only voyage legs 2 and 3 SFRs i.e $430.8 \mathrm{~g} / \mathrm{kWh}$ as compared to the SFR of $528 \mathrm{~g} / \mathrm{kWh}$ recorded by the KYMA energy performance monitoring system. This gives SFR estimation error of $97.2 \mathrm{~g} / \mathrm{kWh}$ which for an
$\mathrm{SHP}_{\text {average }}$ of $8290 \mathrm{~kW}$ amounts to 1.85 tons extra fuel consumption by the ship.

Table 1(a)- Vessel SFR Data January 2014

\begin{tabular}{|c|c|c|c|c|c|c|}
\hline \multirow{2}{*}{$\begin{array}{c}\text { Voyage } \\
\text { Legs }\end{array}$} & \multicolumn{3}{|c|}{ Day 11 } & \multicolumn{3}{c|}{ Day 17 } \\
\cline { 2 - 7 } & kW & T, hr & $\begin{array}{c}\text { F.O, } \\
\text { ton }\end{array}$ & $\begin{array}{c}\text { SHP } \\
\text { kW }\end{array}$ & T, hr & $\begin{array}{c}\text { F.O, } \\
\text { Ton }\end{array}$ \\
\hline Leg 1 & 8903 & 0.1 & 0.3 & 3624 & 4.7 & 9 \\
\hline Leg 2 & 6899 & 1.9 & 7.1 & 6147 & 9.3 & 29.5 \\
\hline Leg 3 & 8404 & 0.3 & 1.2 & -- & -- & -- \\
\hline Leg 4 & -- & -- & -- & -- & -- & -- \\
\hline Leg 5 & -- & -- & -- & -- & -- & -- \\
\hline Leg 6 & -- & -- & -- & -- & -- & -- \\
\hline Leg 7 & -- & -- & -- & -- & -- & -- \\
\hline Leg 8 & -- & -- & -- & -- & -- & -- \\
\hline Leg 9 & -- & -- & -- & -- & -- & -- \\
\hline Leg 10 & -- & -- & -- & -- & -- & -- \\
\hline Leg 11 & -- & -- & -- & -- & -- & -- \\
\hline Leg 12 & -- & -- & -- & -- & -- & -- \\
\hline SHPavg & \multicolumn{7}{|c|}{8290} & & \multicolumn{5}{|c|}{} \\
\hline
\end{tabular}

Table 1(b)- Vessel SFR Data January 2014

\begin{tabular}{|c|c|c|c|c|c|c|}
\hline \multirow{2}{*}{$\begin{array}{c}\text { Voyage } \\
\text { Legs }\end{array}$} & \multicolumn{3}{|c|}{ Day 27 } & \multicolumn{3}{c|}{ Day 25 } \\
\cline { 2 - 7 } & $\mathrm{kW}$ & $\mathrm{T}, \mathrm{hr}$ & $\begin{array}{c}\text { F.O } \\
\text { ton }\end{array}$ & $\begin{array}{c}\text { SHP } \\
\mathrm{kW}\end{array}$ & $\begin{array}{c}\mathrm{T}, \mathrm{hr} \\
\text { F.O }\end{array}$ & $\begin{array}{c}\text { F.O } \\
\text { ton }\end{array}$ \\
\hline Leg 1 & 8419 & 0.1 & 0. & 5795 & 1.1 & 4.2 \\
\hline Leg 2 & 8979 & 0.9 & 3.6 & 5345 & 0.7 & 2.4 \\
\hline Leg 3 & -- & -- & -- & 12398 & 2 & 10.5 \\
\hline Leg 4 & -- & -- & -- & 14126 & 14 & 77.5 \\
\hline Leg 5 & -- & -- & -- & 16940 & 2.1 & 12.6 \\
\hline Leg 6 & -- & -- & -- & -- & -- & -- \\
\hline Leg 7 & 7070 & 0.4 & 1.5 & 6343 & 3.9 & 13.6 \\
\hline Leg 8 & 9196 & 0.8 & 3.8 & 5320 & 0.1 & 0.3 \\
\hline Leg 9 & -- & -- & -- & -- & -- & -- \\
\hline Leg 10 & -- & -- & -- & -- & -- & -- \\
\hline Leg 11 & -- & -- & -- & -- & -- & -- \\
\hline Leg 12 & -- & -- & -- & -- & -- & -- \\
\hline SHPavg & \multicolumn{3}{|c|}{9893.54} & \multicolumn{3}{|c|}{12629} \\
\hline
\end{tabular}

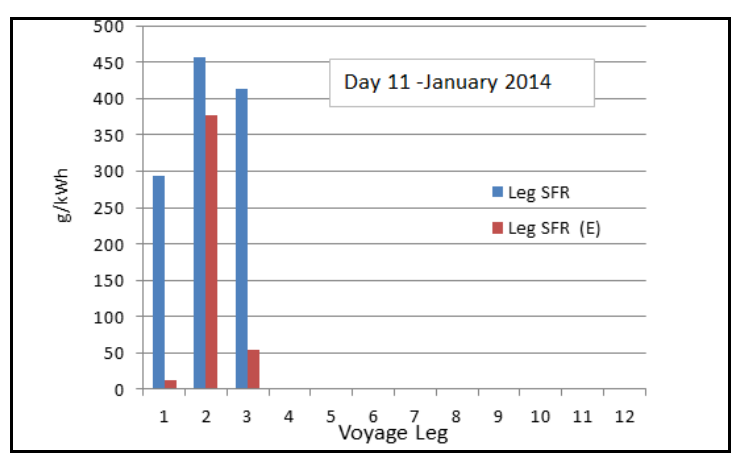

(a)

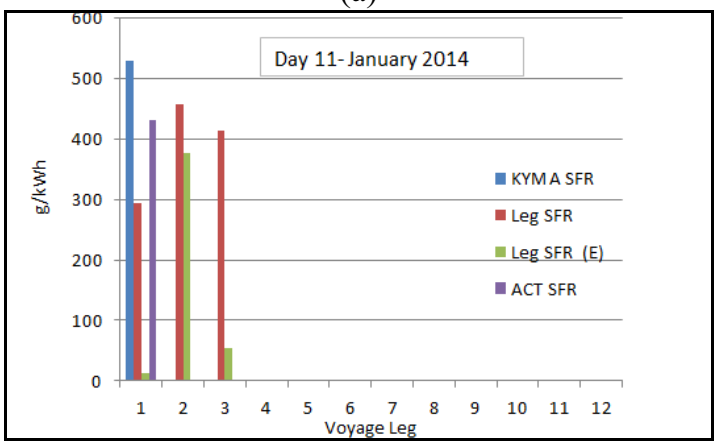

(b)

Figure 2 SFR Recorded versus estimated 
For a voyage duration of 2.3 hours this is a significant estimation error in the KYMA energy efficiency monitoring system.

The voyage leg SFR, effective voyage Leg SFR(E), effective SFR and KYMA recorded SFR for day 11 in figure 2(b) clearly indicate that the actual effective SFR estimate from voyage leg analysis is more accurate than the SFR recorded by KYMA EE monitoring system. Similar analysis results of the daily report data for day 17 January is shown in figure 3(a,b). As expected, the day's effective SFR estimate is lower than the recorded KYMA SFR. The reason why voyage leg analysis method gives lower SFR values is obvious because it filters out fuel consumption of non-standard operations from the day's total fuel consumption and improve EE estimates.

Though, filtering spurious and non-standard operations by using voyage leg analysis method give lower and more accurate effective SFR estimates as shown in figures $2 \& 3$ but still in absolute terms the values on most days in January/February are above the sea trial benchmark of $300 \mathrm{~g} / \mathrm{kWh}$. This indicates that removal of spurious and non-standard operating conditions from the daily report data in figures $2 \& 3$ has not been fully achieved and further filtering of daily report data is still necessary to obtain ship actual SFR which truly reflects the hull and machinery conditions.

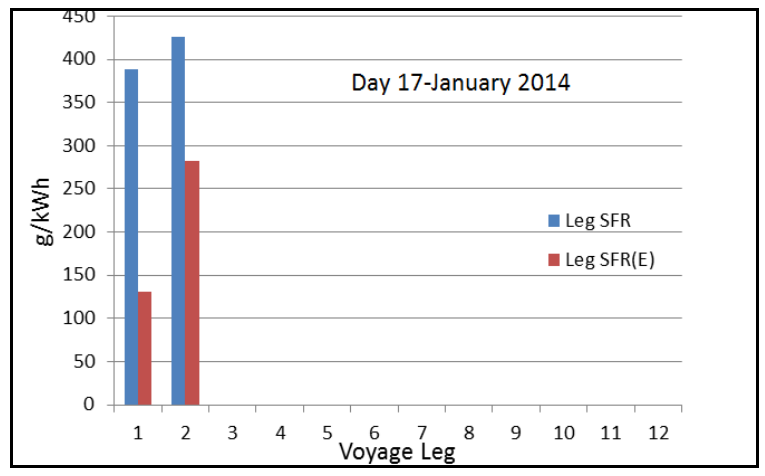

(a)

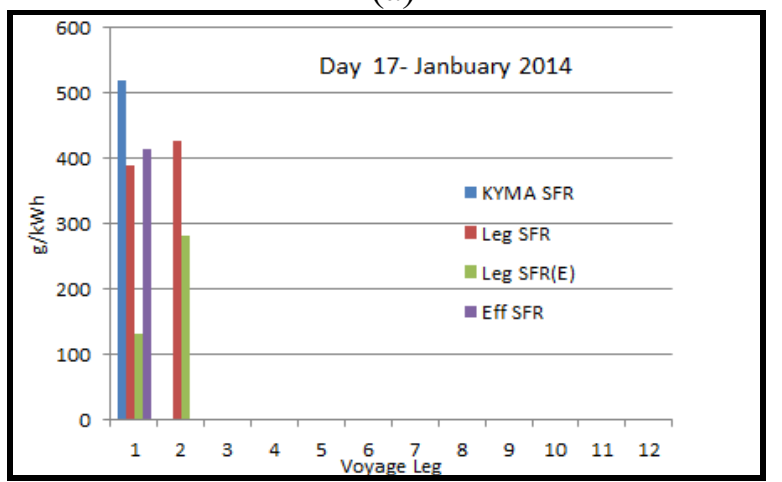

(b)

Figure 3 SFR recorded versus estimated

To improve data filtering method further, daily reports of 22,23,24 and 30 January 2014 have been analyzed. As the KYMA SFRs recorded on those days closely agree with the sea trials benchmark of $300 \mathrm{~g} / \mathrm{kWh}$, this analysis is expected to reveal underlying physics of improved filtering. Table 2 shows daily report data which are used for estimating effective SFR for those days.

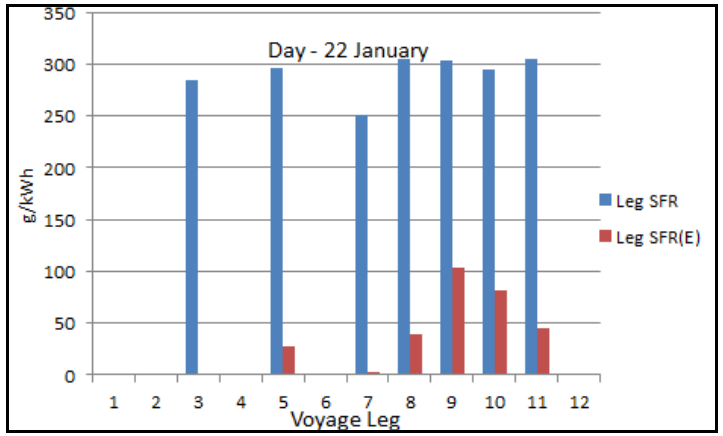

(a)

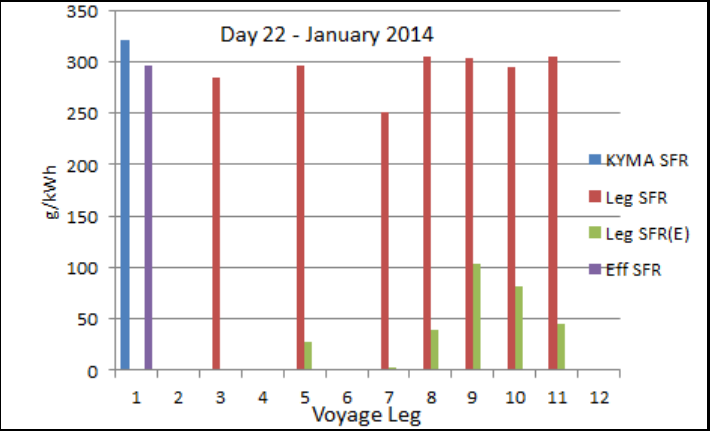

(b)

Figure 4 SFR recorded versus estimated

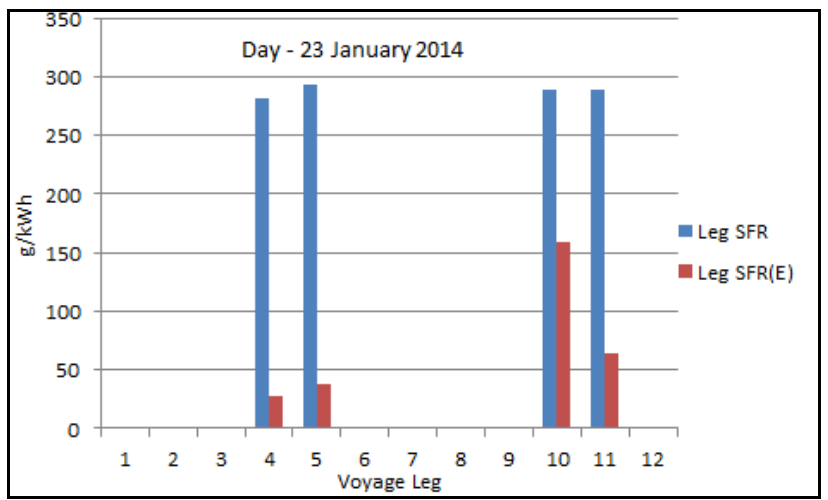

(a)

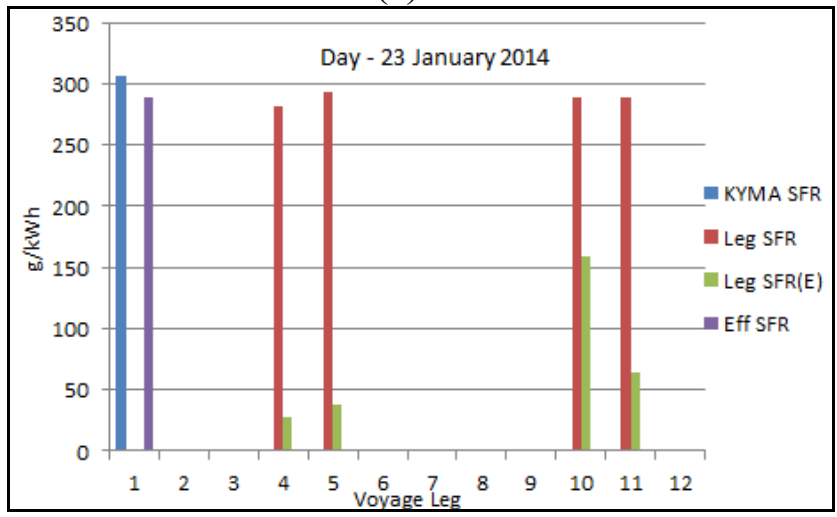

(b)

Figure 5 SFR recorded versus estimated

On day 22, figure 4, voyage legs 3 and 7 have negligible contribution to the overall day's SFR and hence can be 
safely ignored. The actual SFR for that day may be the sum of the remaining voyage legs which adds to 297 $\mathrm{g} / \mathrm{kWh}$ as against the KYMA recorded SFR of 321 $\mathrm{g} / \mathrm{kWh}$. Contrarily, on day 23 , all four voyage legs make significant contribution, figure 5 which indicates absence of any spurious or non-standard operation. The effective SFR is thus the total sum of all voyage legs.

Table 2 - Vessel SFR Data January 2014

\begin{tabular}{|c|c|c|c|c|c|c|}
\hline $\begin{array}{c}\text { Voyage } \\
\text { Legs }\end{array}$ & $\begin{array}{c}\text { SHP, } \\
\mathrm{kW}\end{array}$ & $\mathrm{T}, \mathrm{hr}$ & $\begin{array}{c}\text { F.O } \\
\text { ton }\end{array}$ & $\begin{array}{c}\text { SHP } \\
\mathrm{kW}\end{array}$ & T, hr & $\begin{array}{c}\text { F.O } \\
\text { ton }\end{array}$ \\
\hline Leg 1 & -- & -- & -- & -- & -- & -- \\
\hline Leg 2 & -- & -- & -- & -- & -- & -- \\
\hline Leg 3 & 19616 & 0.1 & 0.6 & -- & -- & -- \\
\hline Leg 4 & -- & -- & -- & 21785 & 2.2 & 14.4 \\
\hline Leg 5 & 21139 & 2.2 & 14.7 & 21667 & 3.0 & 20.3 \\
\hline Leg 6 & -- & -- & -- & -- & -- & -- \\
\hline Leg 7 & 18424 & 0.2 & 1.0 & -- & -- & -- \\
\hline Leg 8 & 18537 & 3.1 & 18.9 & -- & -- & -- \\
\hline Leg 9 & 19344 & 8.2 & 51.7 & -- & -- & -- \\
\hline Leg 10 & 21272 & 6.6 & 44.3 & 21758 & 12.7 & 84.9 \\
\hline Leg 11 & 21281 & 3.5 & 24.3 & 21722 & 5.1 & 34.1 \\
\hline Leg 12 & -- & -- & -- & -- & -- & -- \\
\hline & \multicolumn{7}{|c|}{21679} & \multicolumn{3}{|c|}{23166} \\
SHPavg & & & \multicolumn{3}{|c}{} \\
\hline
\end{tabular}

Table 3(a) SFR Estimated versus KYMA

\begin{tabular}{|l|c|c|c|c|}
\hline \multirow{2}{*}{ Voyage } & \multicolumn{5}{|c|}{ Day - 11 January 2014 } \\
\cline { 2 - 5 } & $\begin{array}{l}\text { Leg } \\
\text { SFR }\end{array}$ & $\begin{array}{l}\text { Leg } \\
\text { SFR(E) }\end{array}$ & $\begin{array}{l}\text { Eff } \\
\text { SFR }\end{array}$ & $\begin{array}{l}\text { SFR } \\
\text { KYMA }\end{array}$ \\
\hline Leg 1 & 294.30 & 12.80 & 430.73 & 528 \\
\hline Leg 2 & 456.27 & 376.92 & - & - \\
\hline Leg 3 & 412.60 & 53.81 & - & - \\
\hline Leg 4 & 0 & 0 & - & - \\
\hline Leg 5 & 0 & 0 & - & - \\
\hline Leg 6 & 0 & 0 & - & - \\
\hline Leg 7 & 0 & 0 & - & - \\
\hline Leg 8 & 0 & 0 & - & - \\
\hline Leg 9 & 0 & 0 & - & - \\
\hline Leg 10 & 0 & 0 & - & - \\
\hline Leg 11 & 0 & 0 & - & - \\
\hline Leg 12 & 0 & 0 & - & - \\
\hline SHPavg & \multicolumn{5}{|c|}{8290} & \\
\hline
\end{tabular}

Table 3(b) SFR, Estimated versus KYMA

\begin{tabular}{|l|c|c|c|c|}
\hline \multirow{2}{*}{ Voyage } & \multicolumn{5}{|c|}{ Day - 17 January 2014 } \\
\cline { 2 - 5 } & $\begin{array}{l}\text { Leg } \\
\text { SFR }\end{array}$ & $\begin{array}{l}\text { Leg } \\
\text { SFR(E) }\end{array}$ & $\begin{array}{l}\text { Eff } \\
\text { SFR }\end{array}$ & $\begin{array}{l}\text { SFR } \\
\text { KYMA }\end{array}$ \\
\hline Leg 1 & 388.64 & 130.47 & 413.30 & 518.60 \\
\hline Leg 2 & 425.77 & 282.83 & - & - \\
\hline Leg 3 & 0 & 0 & - & - \\
\hline Leg 4 & 0 & 0 & - & - \\
\hline Leg 5 & 0 & 0 & - & - \\
\hline Leg 6 & 0 & 0 & - & - \\
\hline & & & & \\
\hline Leg 7 & 0 & 0 & - & - \\
\hline Leg 8 & 0 & 0 & - & - \\
\hline Leg 9 & 0 & 0 & - & - \\
\hline Leg 10 & 0 & 0 & - & - \\
\hline Leg 11 & 0 & 0 & - & - \\
\hline Leg 12 & 0 & 0 & - & - \\
\hline SHPavg & \multicolumn{5}{|c|}{6602} & \\
\hline
\end{tabular}

Table 4(a) SFR, Estimated versus KYMA

\begin{tabular}{|l|c|c|c|c|}
\hline Voyage & \multicolumn{5}{|c|}{ Day - 22 January 2014 } \\
\cline { 2 - 5 } & $\begin{array}{l}\text { Leg } \\
\text { SFR }\end{array}$ & $\begin{array}{l}\text { Leg } \\
\text { SFR(E) }\end{array}$ & $\begin{array}{l}\text { Eff } \\
\text { SFR }\end{array}$ & $\begin{array}{l}\text { SFR } \\
\text { KYMA }\end{array}$ \\
\hline Leg 1 & 0 & 0 & 296.92 & 321.00 \\
\hline Leg 2 & 0 & 0 & - & - \\
\hline Leg 3 & 284.61 & 1.20 & - & - \\
\hline Leg 4 & 0 & 0 & - & - \\
\hline Leg 5 & 295.60 & 27.2 & - & - \\
\hline Leg 6 & 0 & 0 & - & - \\
\hline Leg 7 & 251.38 & 2.10 & - & - \\
\hline Leg 8 & 304.80 & 39.53 & - & - \\
\hline Leg 9 & 303.00 & 103.95 & - & - \\
\hline Leg 10 & 295.20 & 81.52 & - & - \\
\hline Leg 11 & 305.23 & 44.70 & - & - \\
\hline Leg 12 & 0 & 0 & - & - \\
\hline SHPavg & \multicolumn{5}{|c|}{21679} & \\
\hline & \multicolumn{5}{|l}{} \\
\hline
\end{tabular}

Table 4(b) SFR, Estimated versus KYMA

\begin{tabular}{|l|c|c|c|c|}
\hline \multirow{2}{*}{ Voyage } & \multicolumn{4}{|c|}{ Day - 23 January 2014 } \\
\cline { 2 - 5 } & Leg SFR & $\begin{array}{l}\text { Leg } \\
\text { SFR(E) }\end{array}$ & $\begin{array}{l}\text { Eff } \\
\text { SFR }\end{array}$ & $\begin{array}{l}\text { SFR } \\
\text { KYMA }\end{array}$ \\
\hline Leg 1 & 0 & 0 & $\begin{array}{c}288.4 \\
5\end{array}$ & 307 \\
\hline Leg 2 & 0 & 0 & - & - \\
\hline Leg 3 & 0 & 0 & - & - \\
\hline Leg 4 & 282.00 & 26.97 & - & - \\
\hline Leg 5 & 293.00 & 38.21 & - & - \\
\hline Leg 6 & 0 & 0 & - & - \\
\hline Leg 7 & 0 & 0 & - & - \\
\hline Leg 8 & 0 & 0 & - & - \\
\hline Leg 9 & 0 & 0 & - & - \\
\hline Leg 10 & 288.34 & 159.21 & - & - \\
\hline Leg 11 & 288.84 & 64.04 & - & - \\
\hline Leg 12 & 0 & 0 & - & - \\
\hline SHPavg & \multicolumn{5}{|c}{23166} \\
\hline & \multicolumn{5}{|l}{} \\
\hline
\end{tabular}

The summary of voyage leg analysis for days $11,17,22$ and 23 January 2014 are shown in tables $3 \& 4$. The voyage leg analysis reveals, when $\mathrm{SHP}_{\text {average }}$ is much lower than the sea trials condition i.e SHP of $24124 \mathrm{kWh}$ then the day effective SFR is much higher than the sea trials benchmark of $300 \mathrm{~g} / \mathrm{kWh}$. But as the value of $\mathrm{SHP}_{\text {average }}$ increases and reach closer to the sea trials condition the day's effective SFR also improves and moves close to the benchmark value of $300 \mathrm{~g} / \mathrm{kWh}$, as shown in tables $3 \& 4$. Therefore apart from voyage duration, strong wind and optimum trim the $\mathrm{SHP}_{\text {average }}$ is another critical parameter of the filter to estimation of accurate SFR from the daily report data.

The difference in effective SFR estimates from voyage leg analysis and KYMA EE monitoring system records arises mainly due to inclusion of non-standard operating conditions in the KYMA monitoring system which are filtered out in the voyage leg analysis method. The selected filter parameters are shown in table 5 . 
Table 5 Data filter Parameters [2,6]

\begin{tabular}{|c|l|l|}
\hline S.No & Parameter & $\begin{array}{l}\text { Filter } \\
\text { limit }\end{array}$ \\
\hline 1 & $\begin{array}{l}\text { Voyage Leg } \\
\text { Duration }\end{array}$ & $\begin{array}{l}<0.5 \\
\text { hour }\end{array}$ \\
\hline 2 & SHPaverage & $\begin{array}{l}>21000 \\
\mathrm{~kW}\end{array}$ \\
\hline 3 & Trim & $\begin{array}{l}< \pm 0.5 \\
\mathrm{~m}\end{array}$ \\
\hline 4 & Wind speed & $\begin{array}{l}<15 \\
\text { knots }\end{array}$ \\
\hline 5 & $\begin{array}{l}\text { Beaufort } \\
\text { Sea State }\end{array}$ & $<3$ \\
\hline
\end{tabular}

\section{Conclusions}

SFR estimate obtained from KYMA energy efficiency monitoring system is based on total fuel consumed during normal and also non-standard short operational voyages. Because of that it does not represent true performance of the main machinery and underwater hull condition. In contrast the effective SFR estimate from voyage leg method is lower than values recorded by the KYMA system because it has been obtained by using a data filter to eliminate the contributions of spurious and non-standard operations of the ship. The Data filter parameters, table 5 , have been selected after analysing contributions of each voyage leg to the ship SFR for a 24 hour passage and those relating to non-standard operating conditions have been ignored or filtered out. This procedure therefore gives effective SFR of the ship coming from only standard operating conditions. The effective SFR can be then used for comparison with the ship benchmark performance index to assess actual condition of ship's underwater hull and machinery.

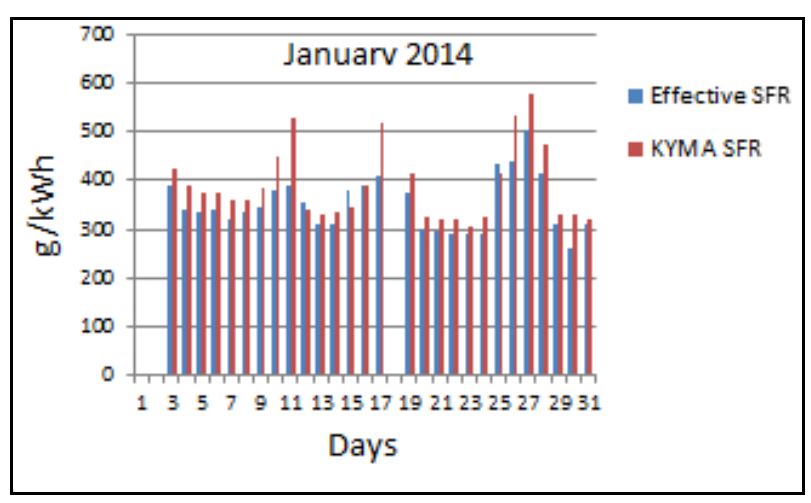

Figure 6 Ship SFR estimate versus KYMA

Comparison of energy efficiency i.e effective SFR of the ship based on voyage leg analysis and those recorded from the KYMA monitoring system for January 2014 in figure 6 indicates voyage leg analysis gives a lower and more accurate SFR estimates.
Glossary:

\begin{tabular}{|c|c|}
\hline $\mathrm{EE}$ & Energy Efficiency \\
\hline SHP & Shaft power, kW \\
\hline LNG & efied Natural Gas \\
\hline YMA SFR & $\begin{array}{l}\text { Specific Fuel Rate calculated by the } \\
\text { Energy Performance monitoring system }\end{array}$ \\
\hline & Specific Fuel Rate of a Voyage Leg \\
\hline & $\begin{array}{l}\text { Net SFR contribution of individual } \\
\text { voyage leg on over all SFR of the day }\end{array}$ \\
\hline ואות & $\begin{array}{l}\text { Estimate of actual SFR after filtering } \\
\text { contribution of nonstandard voyages }\end{array}$ \\
\hline
\end{tabular}

\section{References}

[1] Tadeusz Borkowski,Lech Kasyk, Przmyslaw Kawalak, Assessment of Ship Engine effective Power - Fuel Consumption and emissions using the vessel speed, Journal of Kones Powertrain and Transport, Vol 18, No2, 2011.

[2] Kevin P Logan, Using Ship Propeller for Hull Condition Monitoring, Presented at ASNE Intelligent Ship Symposium IX, 25 May 2011, Philadelphia, PA,USA

[3] Jonas Kallman, Ship Power Estimation for Marine Vessels Based on System Identification, Thesis, Department of electrical Engineering LIKOPINGS University, SF-581 83 Linkoping, Sweden.

[4] Sinha R P, Fuel Efficient Ship Operation - An Optimization Approach, $6^{\text {th }}$ International Engineering Conference (ENCON 2013) 1-4 July 2013, Kuching, Malaysia

[5] Thomas Hellstrom, Optimum Pitch, Speed and Fuel Control at Sea, Journal of Marine Sciences and Technology, Vol 12, No2 pp 71-77(2004)

[6] Stefan Petursson, Predicting Optimal Trim Configuration of Marine Vessels with respect to fuel usage, Master Thesis, School of Engineering and Natural Sciences, University of Iceland, Reykjavik 2009

[7] Rashad A, Maihy A. EL , Energy and Exergy Analysis of Steam Power Plant in Egypt, International Conference on Aerospace Sciences \& Aviation Technology, ASAT-13, May 26-28 2009, asat@mtc.edu.eg

[8] Sinha R P, Wan M Norsani Wan Nik, Energy Analysis of Steam Power Plant of a Medium Size LNG Tanker, International Conference on Maritime Technology , Kuala Terengganu, 2012.

[9] Zabi Bazari, Tore Longva, Assessment of IMO Mandated Energy Efficiency measures for International L:ILED \INF\PRESS $2011 \backslash$ EEDI Shipping, Presentation $\backslash$ Report. 